\title{
DIGITAL TRANSFORMATION OF RUSSIA ENERGY SECTOR: METHODS AND INTELLIGENT TECHNOLOGIES OF SCIENTIFIC SUBSTANTIATION OF STRATEGIC DECISIONS
}

\author{
Lyudmila V. Massel ${ }^{1^{*}}$, Aleksei G. Massel ${ }^{1}$ \\ ${ }^{1}$ Melentiev Energy Systems Institute of SB RAS, 664130 Irkutsk, st. Lermontov 130
}

\begin{abstract}
The problems of energy sector digital transformation in Russia are considered. The problem of insufficient use of the results available in scientific organizations of the energy profile is highlighted. Attention is drawn to the need for intelligent support for the justification and adoption of strategic decisions on the development of technological infrastructure (digital transformation of energy sector). An approach is proposed to solve the problem of integration of software, information support and intelligent information technologies developed at Melentiev Energy Systems Institute of SB RAS. The architecture of a multiagent intelligent environment providing this integration, and a multi-agent methodological approach to its development are considered.
\end{abstract}

Keywords. Digital energy sector, intelligent information technologies, mathematical and semantic modeling, knowledge management, fractal stratified model, multi-agent systems.

\section{Introduction}

In connection with the spread of the concepts of Smart Grid [1-2] and digital energy sector [3] in Russia , it is necessary to take into account that when solving the problems of transition to Smart Grid and digital energy sector, two interrelated areas are distinguished: technological infrastructure and information and telecommunication infrastructure. The success of the digital transformation of the energy industry largely depends on the successful application of modern information technologies. In turn, talking about the application of the latter makes sense if there is a developed modern technological infrastructure. Solutions for the development of technological infrastructure, of course, belong to the class of strategic decisions. To justify and support the adoption of such decisions, it is advisable to use intelligent information technology. This is primarily the technology of semantic modeling and knowledge management, which the team, under the guidance of the authors, develops and uses to create intelligent systems for supporting strategic decision-making in the energy sector. An approach to the construction of such intelligent system (multi-agent tool environment) is proposed, integrating those developed at the ISEM SB RAS mathematical and semantic methods and models and software tools for their support.

\section{Problems of transition to digital energy industry}

The relevance of the scientific justification of strategic decisions on the digital transformation of energy industry is due to the need to solve a number of problems that arise in this case.

As noted in the expert-analytical report of the Center for Strategic Research "Digital Transition in the Electric Power Industry of Russia" [4], in many developed countries of the world, scenarios are being implemented that transform the electric power industry on the basis of client-centric distributed architecture of power systems (this area is usually called energy transition). This transition is focused on the large-scale use of distributed renewable energy, on attracting private investment and the formation of decentralized markets. It also implies the intellectualization of infrastructure and the transition of consumers to active, prosumeristic behaviors: consumers are turning into electricity suppliers. The challenges for the Russian electric power industry have their own characteristics, which is associated with an excess of traditional fuel and energy resources, a large and extended territory with a low density of the network of populated areas, and specific socio-economic factors. But at the same time, they resonate with global challenges and challenges for countries with similar conditions. We are talking about the transition to a new technological paradigm in the electric power industry, which represents the organization of energy supply in the retail sector as an ecosystem of energy producers and consumers that seamlessly integrate into the common infrastructure and exchange of energy resources. This approach, by analogy with the ongoing interactions, is also called "Internet of Energy" [4].

\footnotetext{
*orresponding author: massel@isem.irk.ru
} 
At the same time, there are a number of problems arising in the transition to digital energy industry. All problems associated with the digital transformation of energy sector, i.e. with the implementation and application in Russia of integrated intelligent energy systems in general and intelligent information and telecommunication technologies in particular, it can be roughly divided into three classes: cognitive and managerial problems, scientific and technological limitations, and personnel problems [3, 5]. The expert-analytical report mentioned above [4] proposes, as one of their institutional and organizational measures, "to create a Russian agency for advanced research and development in the field of energy (by analogy with ARPA-E in the USA." The experience of system studies in the energy and results of research, both ISEM SB RAS, and other research organizations in the energy field is ignored.

\section{System studies of energy industry}

MESI SB RAS is one of the leaders in the field of system research in the energy sector of Russia [6].

Until recently, the main research tool was mathematical modeling and a computational experiment. In connection with the new development trends of the Russian energy sector (Smart Grid and Digital Energy), much attention is paid to the development and application of intelligent information technologies.

The Digital Economy Program being implemented in Russia is now being actively developed. The federal project "Digital Energy Industry" is a part of this Program. The authors believe that the federal project "Digital Energy Industry" does not pay enough attention to such areas as intelligent support of strategic decisionsmaking on the development of the technological infrastructure of the energy sector and ensuring cyber security of critical energy facilities. Below we consider in more detail the first direction. A major role in strategic decisions-making should be played by their scientific justification, for which the scientific achievements of the institute can be used.

Traditionally, the ISEM SB RAS uses a hierarchical research scheme in which at higher aggregated level researches of the fuel and energy complex (economic and mathematical models are used) and industry energy systems studies at the next levels (physical and mathematical models are used). These models must coordinated. Research on forecasting the development of the fuel and energy complex is carried out at the top level, taking into account the results obtained in studies of the development of industrial energy systems at the following levels. The scheme includes a number of blocks, each of which corresponds to a set of mathematical methods, models, and software systems that are used to perform computational experiments using these methods and models [6].

To use the results of these studies in substantiating strategic decisions on the digital transformation of energetics, it is necessary to carry out a formal integration of software and information support in order to improve the hierarchical technology to justify the development of the energy industry as a whole and its industry and territorial components, while the main attention should be paid to the development of software and information interfaces between tasks in the horizontal (between energy systems ) and vertical (Energy Systems - Fuel and Energy Complex - External Conditions).

\section{The proposed approach to solving the problem of integration of software, information support and intelligent information technologies.}

Implementation of the proposed integration capabilities can be provided on the basis of the following information technologies: a) a common information and communication environment for software components; b) semantic integration of data, knowledge and software components; c) tools for situational management and semantic modeling.

It is proposed to implement a unified information and communication environment for the interaction of software components in the form of a cloud service, which will provide network access on demand to a common pool of configurable computing resources (for example, servers, storage devices, applications and services, etc.). To ensure the necessary level of security, it is advisable to implement the information and communication environment in the form of a corporate cloud [7].

For semantic integration of data, knowledge and software components, it is proposed to use the concept of knowledge management and apply, as a methodological, author fractal approach to structuring knowledge [8, 9].

To justify strategic decisions on the digital transformation of energy industry, it is proposed to integrate mathematical and semantic modeling tools. Below we consider the concepts and content of semantic modeling [10-12]. A semantic model in a generalized form is an information model that reflects the concepts of the subject area and the relationship between them. 
The authors consider semantic modeling on the example of ontological, cognitive, event and probabilistic (based on Bayesian trust networks) models [13-15]. Table 1 shows a comparison of semantic modeling technologies applied for energy security research.

Table 1. Comparison of ontological, cognitive, event and probabilistic modelling

\begin{tabular}{|c|c|c|c|}
\hline Technology & $\begin{array}{l}\text { Purpose of } \\
\text { Using }\end{array}$ & $\begin{array}{c}\text { Formalizati } \\
\text { on } \\
\text { Apparatus }\end{array}$ & $\begin{array}{c}\text { Use in energy } \\
\text { security (ES) } \\
\text { research }\end{array}$ \\
\hline $\begin{array}{l}\text { Ontology } \\
\text { modeling }\end{array}$ & $\begin{array}{l}\text { To describe } \\
\text { declarative } \\
\text { pieces of } \\
\text { knowledge }\end{array}$ & $\begin{array}{c}\text { Ontologies } \\
\text { (Special } \\
\text { languages } \\
\text { (OWL, } \\
\text { RDF, } \\
\text { XML, } \\
\text { etc.)) }\end{array}$ & \begin{tabular}{|c} 
For the \\
identification, \\
classification \\
and \\
specification of \\
basic concepts \\
in energy \\
research
\end{tabular} \\
\hline $\begin{array}{l}\text { Cognitive } \\
\text { modeling }\end{array}$ & $\begin{array}{l}\text { To identify } \\
\text { causal } \\
\text { relationships } \\
\text { of concepts }\end{array}$ & $\begin{array}{l}\text { Cognitive } \\
\text { maps } \\
\text { (graph } \\
\text { theory) }\end{array}$ & $\begin{array}{l}\text { For analysis } \\
\text { of energy } \\
\text { security } \\
\text { threats }\end{array}$ \\
\hline $\begin{array}{c}\text { Event } \\
\text { modeling }\end{array}$ & $\begin{array}{c}\text { To build } \\
\text { behavioral } \\
\text { models. } \\
\text { Identification } \\
\text { of the } \\
\text { development } \\
\text { dynamics of } \\
\text { emergency }\end{array}$ & $\begin{array}{c}\text { Event } \\
\text { Maps } \\
\text { ( Joiner } \\
\text { Networks } \\
\text { Theory ) }\end{array}$ & $\begin{array}{c}\text { To analyze the } \\
\text { development } \\
\text { and } \\
\text { consequences } \\
\text { of emergencies }\end{array}$ \\
\hline $\begin{array}{c}\text { Probabilistic } \\
\text { modeling }\end{array}$ & $\begin{array}{c}\text { Construction } \\
\text { of } \\
\text { probabilistic } \\
\text { models. Risk } \\
\text { assessment } \\
\text { of ES threat } \\
\text { implementati } \\
\text { on }\end{array}$ & $\begin{array}{l}\text { Bayesian } \\
\text { Trust } \\
\text { Network }\end{array}$ & $\begin{array}{c}\text { To assess the } \\
\text { risks of } \\
\text { emergencies }\end{array}$ \\
\hline
\end{tabular}

Semantic models are developed on the basis of expert knowledge and allow the use of both explicit and implicit knowledge based on the experience, erudition and intuition of experts. For example, cognitive models that display causal relationships can be used to describe and analyze scenarios of external relations of the fuel and energy complex, scenarios of economy development and development of the fuel and energy complex. Event and probabilistic models allow us to consider options for the development of various situations determined by the selected scenarios. After an expert evaluation of various development variants using semantic models, traditional software systems that implement mathematical models of industry-specific energy systems and fuel and energy complex are used and optimization tasks are solved to justify the recommended solutions.

The situational management concept is used by the authors in accordance with the works of D.A. Pospelov and his students [16]. Recently, it is proposed to use this concept for operational control, but the authors believe that it is possible and advisable to apply it in the field of substantiation of strategic decisions. The modern interpretation of situational management, formulated in [17], is used. The authors are proposed to use the situational management concept to justify and support decision-making to ensure energy security. This is considered, in particular, in [18-19].

To justify strategic decisions in the energy sector, it is proposed to integrate mathematical and semantic modeling tools [20]. In this case, both basic technologies are used: agent-oriented and cloud computing, and problem-oriented: semantic and mathematical modeling and two-level research technology, integrating semantic and mathematical modeling and supporting its intelligent IT environment, including semantic modeling tools and providing the ability to integration with traditional software systems [11].

For the traditional scheme of energy systems research described above, the following research levels (stages) and the supporting tools are identified (Fig. 1). The integration of tools is carried out using the knowledge management language.

To support the adoption of strategic decisions in the energy sector using the proposed methodological approach and scientific prototypes of tools, the architecture of a multi-agent intelligent environment (MAIE) has been developed (Fig. 2). 


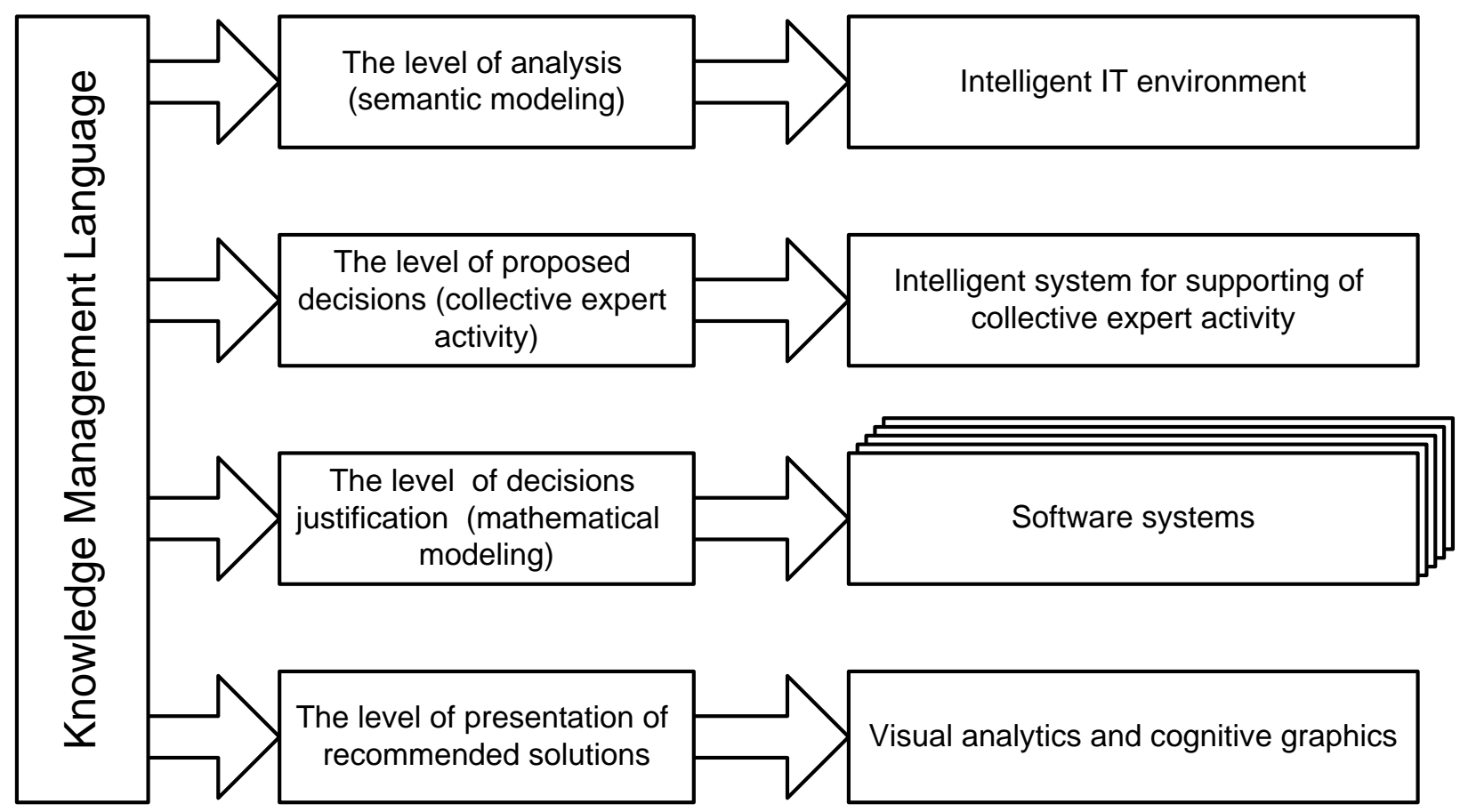

Fig. 1. Levels (stages) of energy systems research and tools supporting them

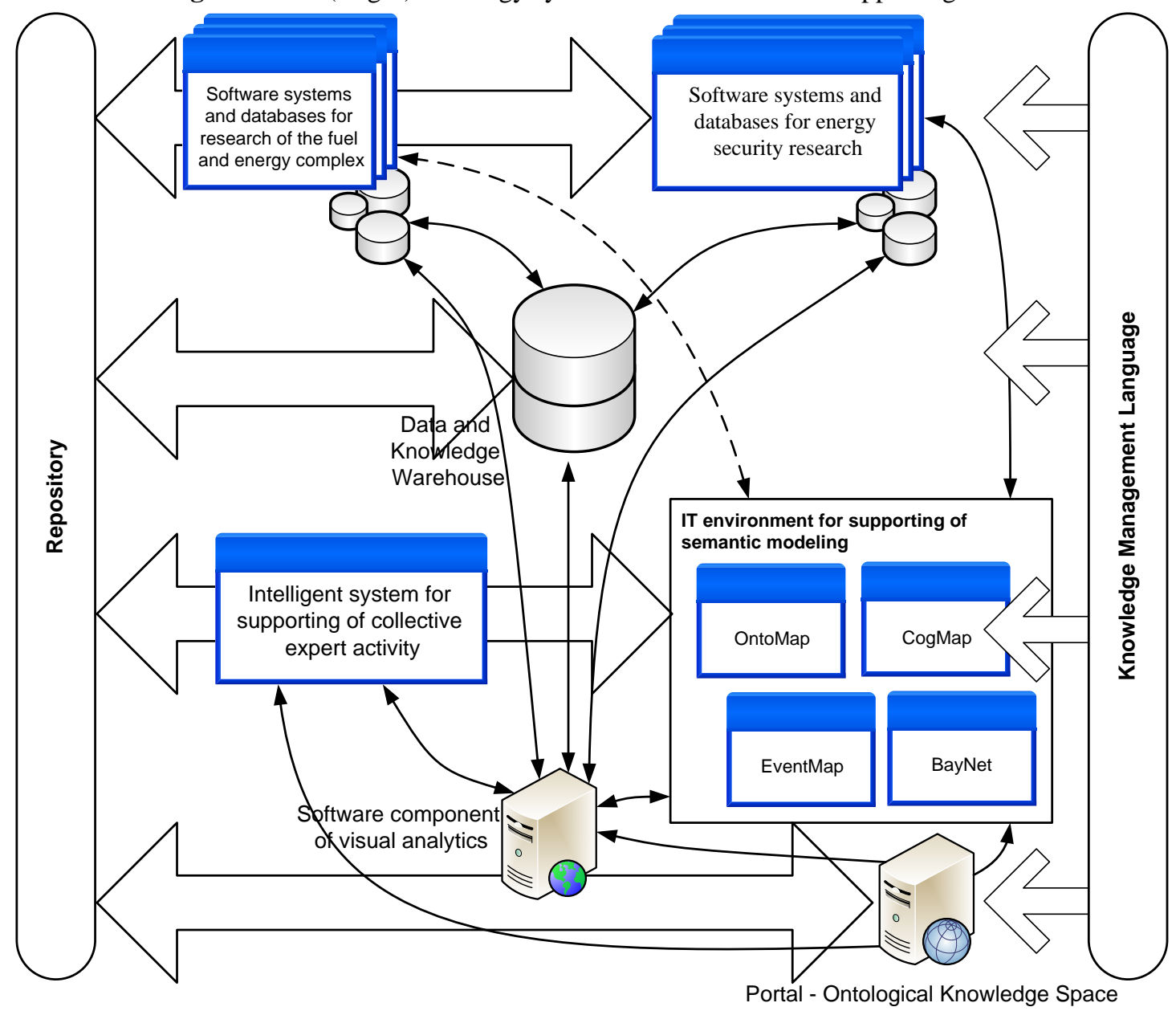

Fig. 2. The architecture of the multi-agent intelligent environment (MAIE) 
This architecture includes:

-Software Systems and Data Bases for research of the fuel and energy complex together with Software and Data Bases, for example, for energy security research;

-Data and Knowledge Warehouse;

-Intelligent system for supporting of collective expert activity;

-Intelligent IT-environment for supporting of semantic modeling;

-Software component for visual analytics (GEOvisualization component);

-Portal - Ontological Knowledge Space.

Knowledge Management Language is used for integration of these components and for call of the required component. The Repository provides storage of descriptions of all components, as well as databases and knowledge bases.

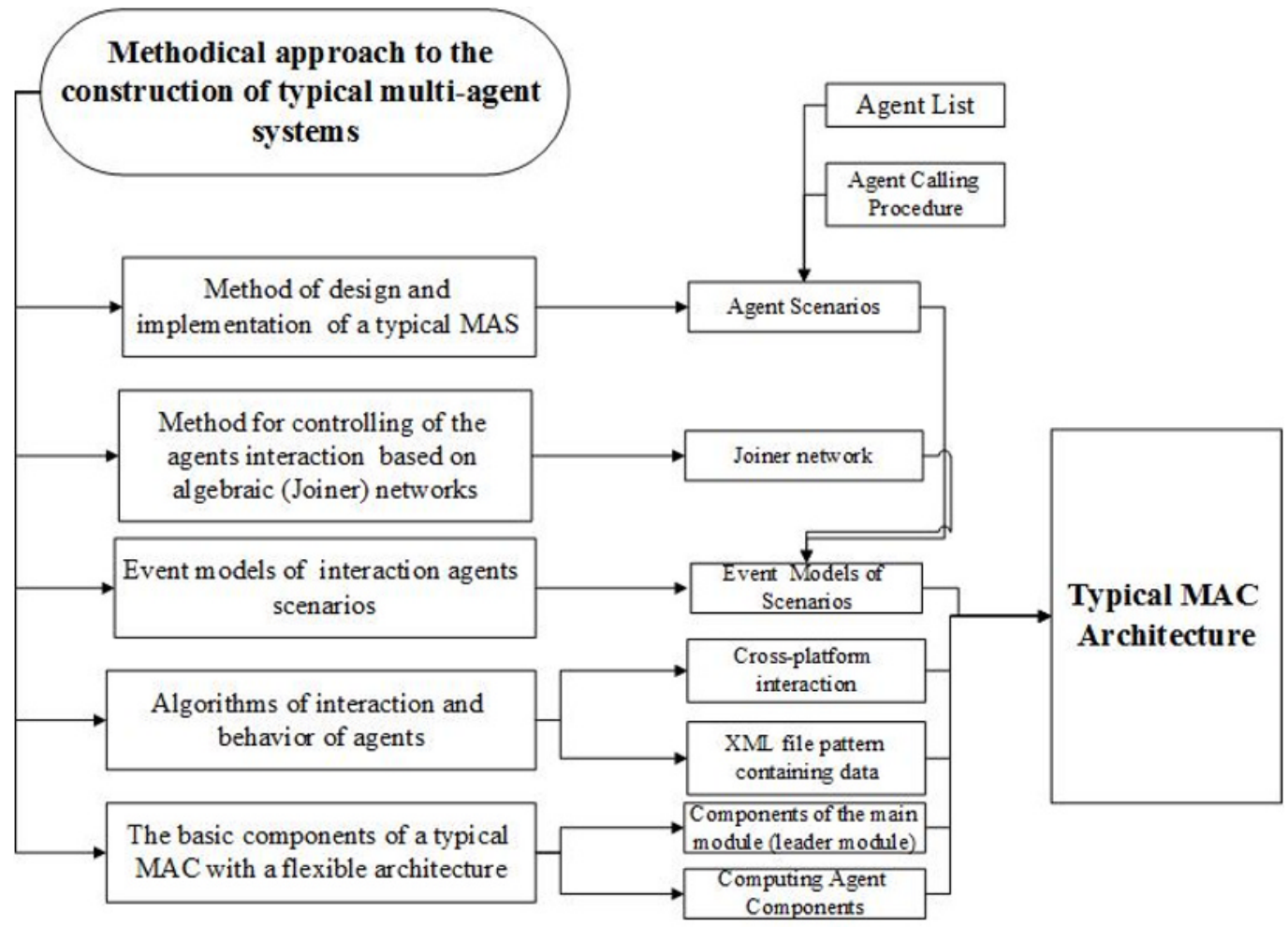

Fig. 3. Methodical approach to the construction of multi-agent systems

\section{Conclusion}

The problems of the transition to digital energy industry are considered, among which stand out, on the one hand, the need of scientific research and available applied technological solutions in this area, and on the other, insufficient attention to the existing results in the field of energy systems research. It is noted that the concept of digital energy does not pay attention to such areas as
Now we have scientific prototypes of all basis components of this scheme. Their adaptation, integration and approbation is required to solve practical problems in this area.

To implement MAIE, it is proposed to use the author's approach to the construction of multi-agent systems [21] (Fig. 3). Its novelty is determined by the fact that a method for interaction controlling of agents on the basis of algebraic networks is proposed, for the implementation of which event models of agents interaction scenarios are developed. This approach was tested, under the guidance of the authors, in the development of a multi-agent system for the state assessing of electric power networks. Currently, a team led by the authors has developed a number of scientific prototypes of the basic components that can be used in the implementation of MAIE. 
semantic models, of situational management concept, of agent, cloud and intelligent computing.

The results were obtained as part of the implementation of the ISEM SB RAS project no. AAAA-A17117030310444-2, some aspects were studied as part of projects supported by grants from the Russian Foundation for Basic Research No. 19-07-00351, No. 18-57-81001 and No. 18-07-00714 .

\section{References}

1. Kobets B.B., Volkova I.O. The innovative development of electric power based on the concept of Smart Grid. M.: IAC Energy, 2010. 208 p. (in Russian).

2. Voropai N.I., Stennikov V.A. Integrated Intelligent Energy Systems // News of the Russian Academy of Sciences. Energy. №1. 2014. Pp. 64-78 (in Russian).

3. Voropay N.I., Gubko M.V., Kovalev S.P., Massel L.V., Novikov D.A., Raikov A.N., Senderov S.M., Stennikov V.A. Problems of the development of digital energy in Russia // Management Problems. № $\quad 1, \quad 2019$. Pp. 2-14. DOI: http://doi.org/10.25728/pu.2019.1.1 (in Russian)

4. Expert and analytical report "Digital transition in the electric power industry of Russia” https://www.csr.ru/issledovaniya/tsifrovoj-perehodv-elektroenergetike-rossii/ (access date 08.10.2018) (in Russian).

5. Materials of the 2nd industry conference "Digital Transformation of the Electric Power Industry of Russia”, Moscow, October 2017: http://digitenergy.ru/ (access date 11.13.2017) (in Russian)

6. Systemic research in the energy sector: Retrospective of scientific directions SEI - ISEM / resp. ed. N.I. Voropay. Novosibirsk: Nauka, 2010 . - 686 p. (in Russian)

7. Massel L.V., Gribova V.V., Kopaygorodsky A.N. "Cloud" structure of energy-information systems // In the book: Innovative Electric Power-21 / Ed. Batenin V.M., Bushuev V.V., Voropay N.I. M .: IC "Energy", 2017. - Pp. 556-577 (in Russian)

8. Massel L.V. Fractal approach to structuring knowledge and examples of its application / Design ontology, 2016. T. 6, № 2 (20). - Pp. 149-161. DOI: 10.18287/2223-9537-2016-6-2-149-161 (in Russian)

9. Massel L.V. Fractal Approach to Constructing Ontological Knowledge Space / Published in: 2018 3rd Russian-Pacific Conference on Computer Technology and Applications (RPC) Publisher: IEEE. Pp. 1-5. DOI: 10.1109/RPC.2018.8482138 https://ieeexplore.ieee.org/xpl/mostRecentIssue.jsp? punumber $=8469127$
10. Gavrilova T.A., Khoroshevsky V.F. Knowledge bases of intelligent systems. St. Petersburg: Peter, 2001 . 384 p. (in Russian)

11. Trachtengerts E.A. Computer decision support. M.: SINTEG, 1998. - 376 p. (in Russian)

12. Stolyarov L.N. The philosophy of event modeling on the example of the scenario of an energy disaster // International Conference "Information Technologies in Science, Education, Telecommunications and Business": proceedings. Ukraine. Gurzuf, 2010. - Pp. 197-200 (in Russian).

13. Massel L.V., Massel A.G. Semantic technologies based on the integration of ontological, cognitive and event modeling // III international scientific and technical conference OSTIS-2013: proceedings. Belarus. Minsk. BSUIR, 2013. - Pp. 247-250 (in Russian).

14. Massel L.V., Massel A.G. Intelligent computing in studies of energy development directions // News of Tomsk Polytechnic University. 2012. T. 321. № 5. Management, computer engineering and computer science. - Pp. 135-141 (in Russian).

15. Massel L.V., Pyatkova E.V. The use of Bayesian trust networks for the intellectual support of research on energy security problems // Vestnik ISTU. № 2, 2012. - Pp. 8-13 (in Russian).

16. Pospelov D.A. Situational management. Theory and practice. Moscow: Science, 1986. - 284 p. (in Russian).

17. Vasiliev V.I., Ilyasov B.G. Intelligent control systems. Theory and practice. M. Radio engineering, 2009 . - 392 p. (in Russian)

18. Pyatkova N.I., Massel L.V., Massel A.G. Methods of situational management in studies of energy security problems. News of the Academy of Sciences. Energy. № 4, 2016 . - Pp. 156-163 (in Russian).

19. L. Massel, A. Massel. Intelligent support tools for strategic decision-making on Smart Grid development / International Conference "Green Energy and Smart Grids” (GESG 2018): Proceedings. Pp. 1-8. DOI: https://doi.org/10.1051/e3sconf/20186902009 https://www.e3sconferences.org/articles/e3sconf/abs/2018/44/conten ts/contents.html

20. Massel L.V. Integration of semantic and mathematical modeling in studies of energy security problems // International Conference "Modeling2012": proceedings. Kiev. IPME NAS of Ukraine, 2012 . - Pp. 270-273 (in Russian).

21. Massel L.V., Galperov V.I. Development of multiagent systems for the distributed solution of energy problems using agent scenarios / Bulletin of Tomsk Polytechnic University. T. 326. № 5, 2015. - Pp. 4553 (in Russian). 